\title{
PET, CT, and MRI Imaging of Neuronal Migration Anomalies in Epileptic Patients
}

\author{
John Falconer, Juhn A. Wada, Wayne Martin and David Li
}

\begin{abstract}
During the investigation of intractable epilepsy, neuronal migration anomalies [NMA] were discovered in three patients. The first patient had abnormally positioned gray matter within the walls of both lateral ventricles. The second patient had a post operative cystic area in the right parietal-occipital lobes and an area of NMA within the right temporal lobe. The third patient had abnormally thickened gray matter in the right operculum. Long term CCTV-EEG monitoring of these three patients revealed ictal discharges originating from the area of abnormal gray matter in patients 2 and 3. PET scanning showed the areas of NMA in all three patients to have similar metabolic activity to normal gray matter. These cases illustrate the value of various imaging modalities and suggest some interesting physiology of a spectrum of neuronal migration anomalies.

RÉSUMÉ: Imagerie par PET, CT et NMR des anomalies de migration neuronale chez les patients épileptiques Lors de l'investigation d'épilepsies réfractaires, des anomalies de la migration neuronale (AMN) ont été découvertes chez trois patients. Le premier patient avait de la substance grise en position anormale dans les parois des deux ventricules latéraux. Le deuxième patient avait une zone kystique post-chirurgicale dans les lobes pariétal et occipital droits et une zone d'AMN dans le lobe temporal droit. Le troisième patient avait une zone de matière grise anormalement épaisse dans d'opercule droit. La surveillance prolongée par CCTV-EEG de ces trois patients a révélé des décharges ictales originant de la zone de matière grise anormale chez les patients 2 et 3 . Le PET scan a montré que les zones d'AMN chez les trois patients avaient une activité métabolique similaire à celle de la matière grise normale. Ces cas illustrent la valeur de différentes techniques d'imagerie et laissent entrevoir des aspects physiologiques intéressants dans différentes anomalies de la migration neuronale.
\end{abstract}

Can. J. Neurol. Sci. 1990; 17:35-39

Cortical gray matter is derived embryologically from the germinal matrix within the neural tube. ${ }^{1}$ Following neuronal proliferation from 2 to 4 months of gestational age, a period of neuronal migration takes place between approximately 3 and 6 months of gestational age. The neuroblasts are thought to migrate along a glial scaffold, and this complex process is subject to breakdown at any time. Neuroblasts which do not complete this migration become 'arrested', and a broad group of anomalies including agyria, pachygyria, polymicrogyria, schizencephaly, unilateral megalencephaly and heterotopic gray matter can result. ${ }^{2,3}$ These areas of abnormally situated gray matter can later become the focus of origin of epileptic activity. ${ }^{4}$ We report the results of investigation of three adult patients discovered to have neuronal migration anomalies [NMA].

\section{METHODS}

These medically intractable epileptic patients were studied with 24 hour/day closed circuit television and continuous EEG recording [CCTV-EEG] lasting for 2-3 weeks. ${ }^{5}$ In addition they all underwent computed tomography (CT), magnetic resonance imaging (MRI), and positron emission tomography (PET). CT was performed on a Somatom DR2 whole body scanner, before and after the administration of intravenous contrast. Transverse slices were $8 \mathrm{~mm}$ thick and contiguous. MRI was performed on a Picker International Vista $2000 \mathrm{MR}$ unit based on a 0.3 Tesla superconducting magnet operating at 0.15 Tesla. Scans were $10 \mathrm{~mm}$ thick and contiguous; they were obtained in transverse, coronal, and sagittal planes in all patients. Pulse sequences employed included an inversion recovery (IR) sequence using a repetition time (TR) of 1650 or $2450 \mathrm{msec}$, inversion time (TI) of $400 \mathrm{msec}$ and echo time (TE) $40 \mathrm{msec}$ and a double echo spin echo (SE) sequence using TR of $2058 \mathrm{msec}$ and TE of 40 and $120 \mathrm{msec}$. PET scans were obtained using the UBC/TRIUMF PETT VI imaging system with Fl8-fluoro-deoxy-glucose (FDG) to study glucose metabolism. This system collects data simultaneously from seven contiguous slices. In plane resolution is $9.2 \mathrm{~mm}$; center to center slice separation is $14 \mathrm{~mm}$. Scans were performed starting 40 minutes after administration of $5 \mathrm{mCi}$ of FDG. A measured attenuation correction was applied to the

From the Division of Neurosciences (J.F., J.A.W.), Division of Neurology (W.M.), Department of Radiology (D.L.), Health Sciences Center Hospital, University of British Columbia, Vancouver

Received January 4, 1989. Accepted in final form October 15, 1989

Reprints not available. Correspondence to: Dr. J. Falconer, 10510 - Hollymount Drive, Richmond, British Columbia, Canada V7E 4Z2 

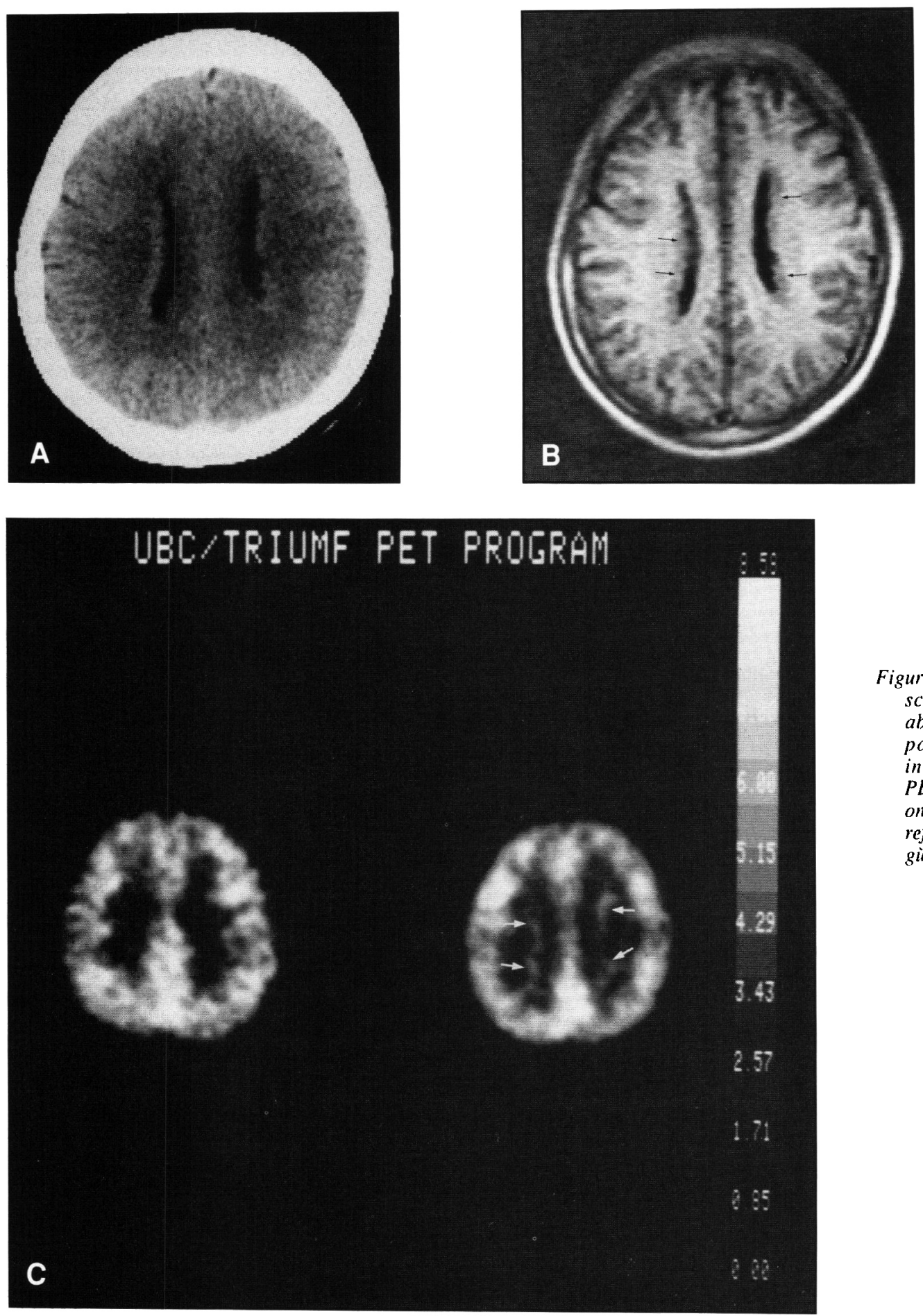

Figure I - Patient I: A) CT scan, B) MRI scan; arrows point to periventricular abnormal tissue. C) PET scan: arrows point to periventricular areas of increased metabolic activity. A normal PET scan at a comparable level is shown on the left. The numbers on the gray scale refer to glucose metabolic rate in $\mathrm{mg} /(100$ gümin).

emission data. All patients had continuous EEG monitoring during the first 30 minutes following isotope injection, and none had any recorded seizure activity during that time.

\section{Case Reports}

Patient 1 - 29 year female:

At the age of two this patient had a single generalized febrile convulsion. She next had an unprovoked generalized tonic-clonic convulsion at age 22 (pattern-1). At age 27 while treated with carbamazepine and phenobarbital, she developed a second type of seizure pattern in which she would get bilateral dysesthesias in her face, which would "shoot over the top" of her head. She would then call out, and start banging with her hands to attract attention. She would make guttural sounds, and lie down usually on her left side. She would retain awareness throughout, and would be unable to speak for a few seconds afterwards (pattern-2). These seizures occurred approximately once a week. Occasionally one of these episodes would lead to a generalized tonicclonic seizure. Her physical examination disclosed borderline low intelligence, and slight hyper-reflexia of her left side without weakness.

CCTV-EEG showed that the pattern-2 seizure was pseudoepileptic, and associated with hyperventilation, but that pattern-l seizures were associated with posterior frontal lobe ictal discharges. CT (Figure 1-a) 

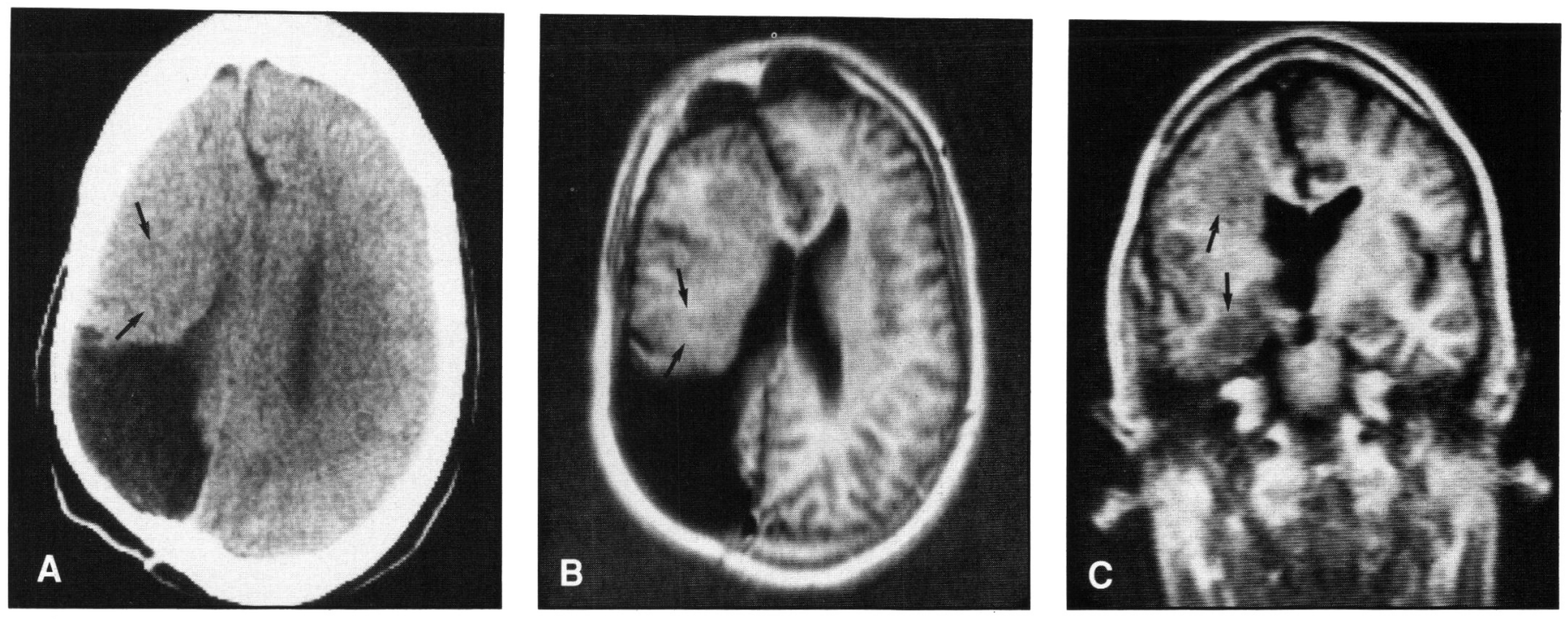

\section{UBC/TRIUMF PET PROGRAM}

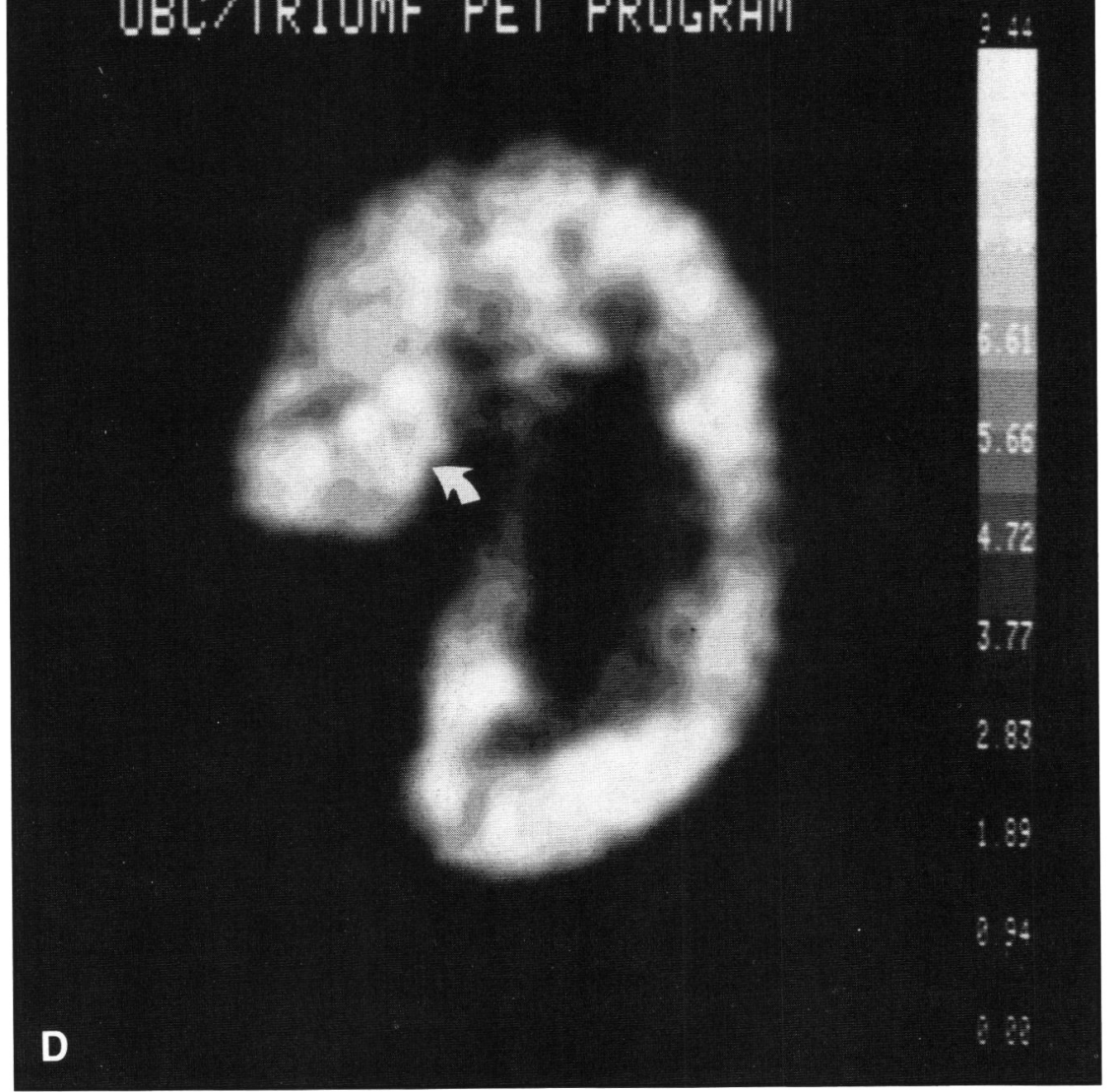

Figure 2 - Patient 2: A) CT scan, B) MRI scantransverse slice, C) MRI scan - coronal slice: arrow' points to area of abnormal tissue. D) PET scan; arrow points to area of increased metabolic activity.

demonstrated small, nodular masses of gray matter lining the walls of both lateral ventricles. The MRI (Figure 1-b) confirmed the abnormally positioned areas of gray matter within the walls of the lateral ventricles, with the same signal characteristics as normal gray matter. The FDG/PET scan (Figure 1-c) showed abnormal areas of increased metabolic activity deep within the centrum semiovale of both hemispheres, above the caudate nuclei. These areas appeared to have a metabolic rate similar to cortical gray matter, although the small size limited accurate quantitation.

Patient 2 - 17 year male:

This patient was delivered by caesarean section at term, following
20 minutes of fetal distress. Several weeks after discharge home he was noted to have an asymmetric right skull and possible focal seizures. "A scar from the right side of the brain" was removed at one month of age, and he was noted to have a left hemiparesis in the immediate post operative period. Since age 4 he has had focal seizures during which his left arm raises unassociated with loss of consciousness, spells during which his whole body becomes hot and his head and neck are flushed bilaterally, and bilateral eye twitching which lasts I to $1 \frac{1 / 2}{2}$ minutes with transient confusion. Physical examination showed moderate mental retardation, a left homonymous hemianopia, and an inability to look to the left voluntarily. There was also a moderate left hemiparesis and decreased primary sensation on the left. 

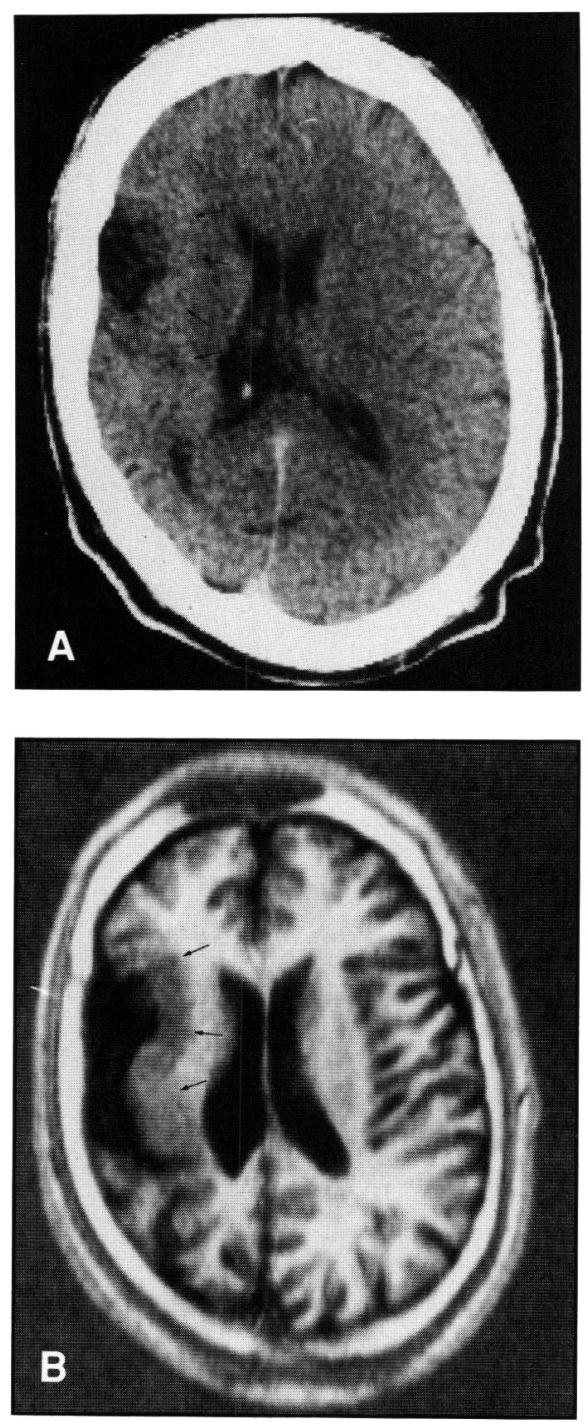

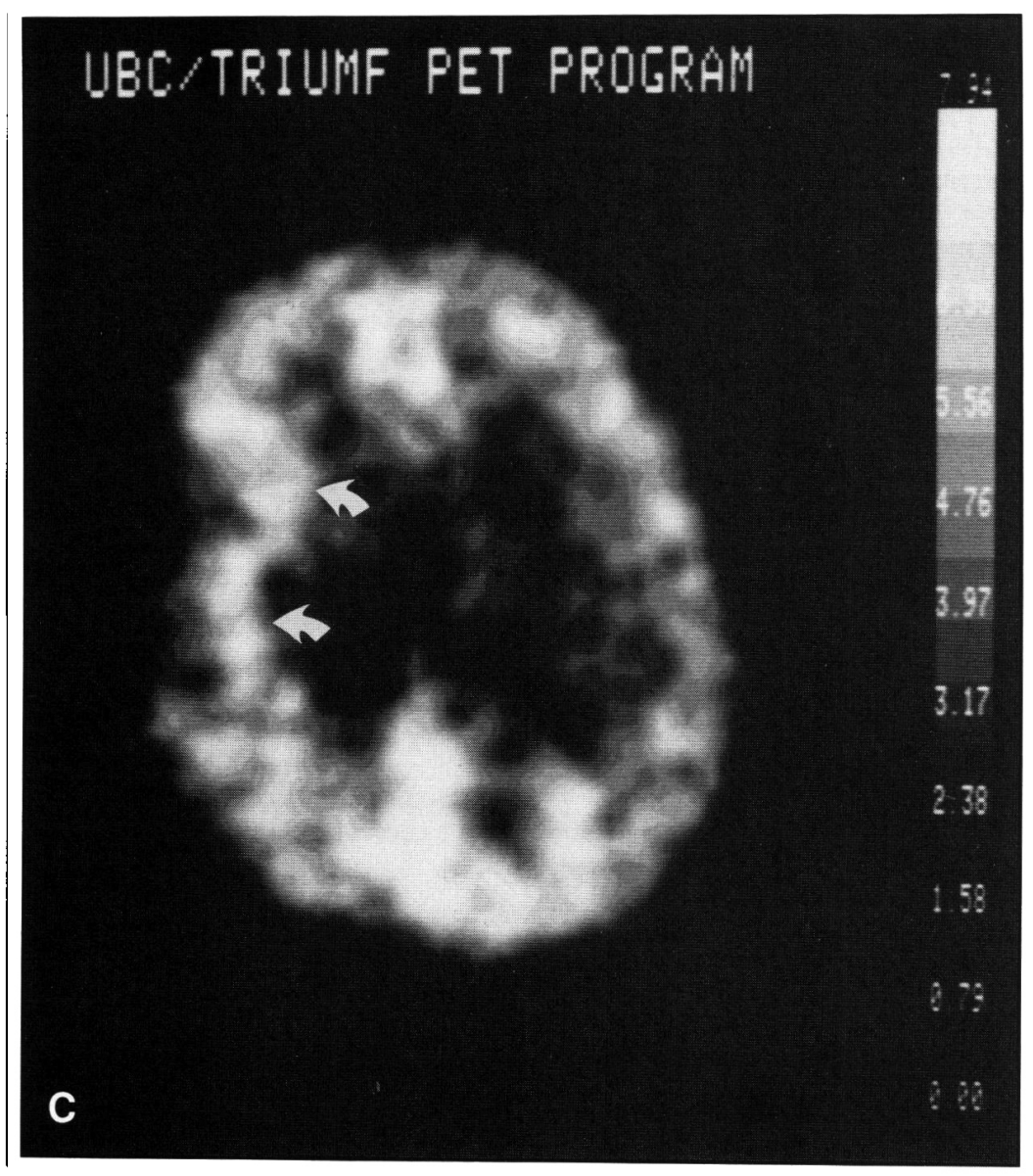

Figure 3-Patient 3: A) CT scan, B) MRI scan; arrow points to area of abnormally thickened cortical gray matter. C) PET scan; arrow points to area of increased metabolic activity.
During CCTV-EEG poly-spike ictal discharges were recorded from the right temporal region. CT (Figure 2-a) showed the area of previous surgery in the right parieto-occipital area as a triangular area of CSF density extending from the body of the right lateral ventricle peripherally. Compared to the left there was relative diminution of white matter around the anterior margin of the lateral ventricle. The IR scans (Figures 2-b, 2-c) showed areas similar to gray matter adjacent to the body of the right lateral ventricle in the expected position of white matter. Increased numbers of closely set, miniature shallow gyri over the cortical surface produced a paradoxically smooth contour suggestive of polymicrogyria. On the coronal scans these changes were seen to involve the operculum as well as the temporal lobe on the right. On the $\mathrm{SE}$ images high signal changes in the cortex were seen over the right temporal lobe but not in the frontal and parietal regions. The FDG/PET scan (Figure 2-d) showed no activity in the area of previous surgery. The right temporal and frontal lobe was seen to have an enlarged area of increased metabolism again comparable to the cortical gray matter.

Patient 3 - 28 year male:

At age 4 this patient began having brief staring spells lasting a few seconds which were not completely controlled with medications. By age 16 he developed "falling attacks"; his eyes would roll back, his head consistently would turn to the right, and he would fall straight backwards. He would remain unconscious and stiff for 5-10 seconds, and then would start pounding his right fist on his right thigh, and make "grunting" sounds. He would remain confused, disoriented, and drowsy for 1 to $11 / 2$ hours. These episodes occurred 2-4 times per week. The physical exam showed the patient to have reduced intelligence, hypoplasia of the entire left side of his body, a left hemiparesis, and left sided spasticity.

Long term CCTV-EEG monitoring showed ictal discharges to originate from the right temporal lobe, and then rapidly generalize. CT (Figure 3-a) showed asymmetry of the brain and cranium, with the right side being smaller than the left. The right lateral ventricle was slightly larger than the left. The right sylvian fissure was widened and there was atrophy of the parieto-temporal operculum. The insular cortex appeared thickened. On MRI (Figure 3-b) the thickened gray matter over the insular cortex was clearly evident on the IR sequence. The cortical surface was smooth with no detectable gyri in the insular cortex and surrounding cortical area. On the SE images very slight increased signal of the cortical gray matter was also present. The FDG/PET scan (Figure 3 c) also demonstrated marked asymmetry, and a thickened area of high metabolic activity in the right temporal lobe, comparable to other areas of gray matter within this patient.

\section{Discussion}

Gray matter heterotopias have been recognized at least since the report of Tungel ${ }^{6}$ in 1859 . Layton ${ }^{7}$ was one of the first to draw attention to these rests of gray matter as being potential foci of seizure activity in adults. In addition, they are associated with sometimes massive fetal anomalies, some incompatible with life. Initial reports of neuronal migration anomalies 
depended on post-mortem histologic diagnosis. In 1967, the identification of NMA within the living patient was described using pneumoencephalography. ${ }^{8,9}$ In 1978 four patients with NMA diagnosed with CT were described.10,11 More recently, reports of MRI in NMA have been described. 12,13,14,15 In 1987, Barkovich et al reported 13 patients expressing a wide range of NMA. ${ }^{16}$ These authors stress that MRI is much more sensitive than other imaging techniques for demonstrating NMA. Bairamian and colleagues have described a single case of heterotopic gray matter which was imaged by CT, MRI, and PET. 17 They stressed that the areas of NMA had the same signal characteristics and glucose utilization values as normal gray matter.

Our three cases demonstrate that although NMA can be seen on CT, MRI demonstrates the abnormalities much more clearly. PET demonstrated the NMA in all three cases, and showed these areas to have similar metabolic activity to normal gray matter. In our two cases with unilateral NMA, 24 hour CCTVEEG monitoring demonstrated the seizure activity to originate from the area of NMA.

Our patients demonstrate a spectrum of neuronal migration disorders. The first patient's periventricular NMA presumably originated from a neuronal migration arrest resulting from a bilateral process occurring very early during development. The second patient's NMA involves much of the temporal and frontal lobe, an obviously more severe migrational arrest with very little development of normal gray matter in those locations. The third patient had abnormally thickened gray matter in the right insular cortex, perhaps representing NMA resulting from laminar necrosis of cortical tissue. 18

Although NMA is a well recognized cause of epilepsy in children, it is less often identified as a cause of seizures in adults. It is only with the advent of high resolution imaging equipment that it can be readily observed during life.

\section{ACKNOWLEDGEMENTS}

Supported in part by grants from the Medical Research Council of Canada, Woodward Foundation, Vancouver Foundation, and Vancouver Society for Epilepsy Research.

\section{REFERENCES}

I. Lemire RJ, Loeser JD, Leech RW, et al. Normal and abnormal development of the human nervous system. Hagerstown: Harper \& Row 1975.
2. Barkovich AJ, Chuang SH, Norman D. MR of neuronal migration anomalies. Am J Neuroradiol 1987; 8: 1009-1017.

3. Barkovich AJ, Norman D. MR imaging in schizencephaly. Am J Neuroradiol 1988; 9: 297-302.

4. Layton, DD. Heterotopic cerebral gray matter as an epileptogenic focus. J Neuropathol 1962; 1(21): 244-249.

5. Panych LP, Wada JA, Beddoes MP. Automation of the seizure investigation unit at the University of British Columbia Health Sciences Centre Hospital. Electroenceph Clin Neurophysiol 1985; 61(6): 588-591.

6. Tungel, C. Ein Fall von Neubildung graner Hirnsubstanz. Archic Path Anat 1859; 16: 166.

7. Layton, DD. Heterotopic cerebral gray matter as an epileptogenic focus. J Neuropathol 1962; I(21): 244-249.

8. Bergeron RT. Pneumographic demonstration of subependymal heterotopic cortical gray matter in children. Am J Roentgenol Radium Ther Nucl Med 1967; 101: 168-177.

9. Mueller, CF. Heterotopic Gray Matter. Radiology 1970; 94: 357 . 358.

10. Mikhael MA, Mattar AG. Malformation of the cerebral cortex with heterotopia of the gray matter. J Comput Assist Tomgr 1978: 2: 291-296.

11. Zimmerman RA, Bilaniuk LT, Grossman RI. Computed tomography in migratory disorders of human development. Neuroradiology 1983; 25: 257-263.

12. Deeb ZL, Rothfus WE, Maroon JC. MR imaging of heterotopic gray matter. J Comput Assist Tomgr 1985; 9(6): 1140-1141.

13. Dunn V, Mock T, Bell WE, et al. Detection of heterotopic gray matter in children by magnetic resonance imaging. Magnetic Resonance Imaging 1986; 4: 33-39.

14. Hayden SA, Davis KA, Stears JC, et al. MR imaging of heterotopic gray matter. J Comput Assist Tomogr 1987; 11 (5): 878-879.

15. Ishikawa A, Fukushima N, Wagatsuma $Y$, et al. Magnetic resonance imaging of heterotopic gray matter. Brain and Development 1987; 9(1): 60-61.

16. Barkovich AJ, Chuang SH, Norman D. MR of neuronal migration anomalies. Am J Neuroradiol 1987; 8: 1009-1017.

17. Bairamian D, Di Chiro G, Theodore WH, et al. MR Imaging and Positron Emission Tomography of Cortical Heterotopia. J Comp Assist Tomgr 1985; 9(6): 1137-1139.

18. Dvorak K, Feit J. Migration of neuroblasts through partial necrosis of the cerebral cortex in newborn rats - contribution to the problems of morphological development and developmental period of cerebral microgyria. Acta Neuropathol (Berl) 1977; 38: 203-212. 